\title{
Heroínas de serie
}

\author{
Game of thrones | HBO | 2011-2019
}

\author{
Ana Cecilia González" \\ Escuela de la Orientación Lacaniana, Argentina \\ Asociación Mundial de Psicoanálisis
}

Recibido: 6 de junio 2019; aceptado: 24 de junio 2019

\begin{abstract}
Resumen
La expansión de la forma-serie -como la denomina G. Wajcman- es el correlato estético-narrativo de la feminización del mundo, según la hipótesis de J.-A. Miller y E. Laurent. Puesto que una mutación de este orden necesariamente acarrea modificaciones subjetivas de gran calado, este texto aborda las "incidencias sociales de la sexualidad femenina" -Lacan dixit-, y sus implicancias éticas, tomando como objeto de análisis la serie de heroínas de Game of Thrones.
\end{abstract}

Palabras Clave: Serie | Lo femenino | ética | psicoanálisis

Heroines of TV series

\begin{abstract}
The expansion of the serial-form -described by G. Wajcman- is the aesthetic and narrative correlate of the feminization of the world, according to a hypothesis by J.-A. Miller y E. Laurent. Given that such a mutation necessarily carries large subjective transformations, this paper addresses the "social incidences of feminine sexuality"- Lacan dixit-and its ethical implications, taking the series of heroines of Game of Thrones as object of analysis.
\end{abstract}

Key Words: Series | lo femenino| ethics | psychoanalisis

\section{La feminización del mundo}

En el marco de un seminario dictado por Jacques-Alain Miller (2005) en colaboración con Eric Laurent en el curso de 1996-1997, publicado bajo el título El Otro que no existe y sus comités de ética, una hipótesis vio la luz:

La multiplicidad incompleta, inventiva, según la lógica de Lacan de la sexuación, está del lado femenino. Lo múltiple y lo inventivo, la apertura del campo sintomático, responde mucho más a la posición femenina que a la masculina y de cierta manera inscribe también el ocaso de lo viril y la promoción de la lógica del no todo, que implica multiplicidad y apertura. (p. 390)

Si esto fuera así, y Miller subraya en ese entonces que se trata de una hipótesis, estaríamos ante una "feminización del mundo".

Veintiún años más tarde, Gérard Wajcman (2018) la da por probada y se ocupa de desplegarla en un libro titula- do Les séries, le monde, la crise, les femmes -las series, el mundo, la crisis, las mujeres, 2018-, título cuya peculiar sintaxis ya nos pone en materia. El autor sostiene que la forma-serie es intrínseca al mundo actual, que ha dejado atrás el régimen del Todo centrado, limitado y jerárquico, para devenir un mundo fragmentario, múltiple, no-todo, ilimitado. Dicho de otro modo: la serie es inherente a la época, porque ésta se caracteriza por la crisis permanente, en la que el Todo ha estallado en mil pedazos.

Esto se vuelve especialmente palpable en la narrativa norteamericana, responsable por las series consumidas a escala planetaria: si America fue el mito de una nación forjado por el cine del siglo XX, las series son el síntoma de una America múltiple, en las que las minorías se han convertido en mayorías. Las series son la crítica y la desconstrucción del mito de la gran nación del norte.

$\mathrm{Y}$ en ese contexto las heroínas de serie comenzaron a multiplicarse, pasando a ocupar un lugar central. Es que

*anaceciliagonzalezr@gmail.com 
hay una íntima afinidad entre las series y las mujeres, y esto, como enseñó Lacan (1982) con sus fórmulas de la sexuación, por razones lógicas y de estructura. Dicho de otro modo: las nuevas heroínas, reinas de las series, son análogas a las series, ambas son de la misma esencia, concluye Wajcman (2018).

Entonces, el triunfo de la forma-serie es el correlato estético-narrativo de la feminización del mundo. Pero es mucho más que eso, puesto que una mutación de este orden necesariamente acarrea modificaciones subjetivas de gran calado, abriendo la pregunta sobre lo que Lacan llamaba "incidencias sociales de la sexualidad femenina" (Lacan, 1999, p. 698), y también, como corolario, sobre las implicancias éticas.

\section{Heroínas de serie, o la serie de heroínas}

¿Qué caracteriza a las nuevas heroínas, reinas de las series? ¿Qué rasgos las definen? ¿Hay acaso algo común entre ellas?

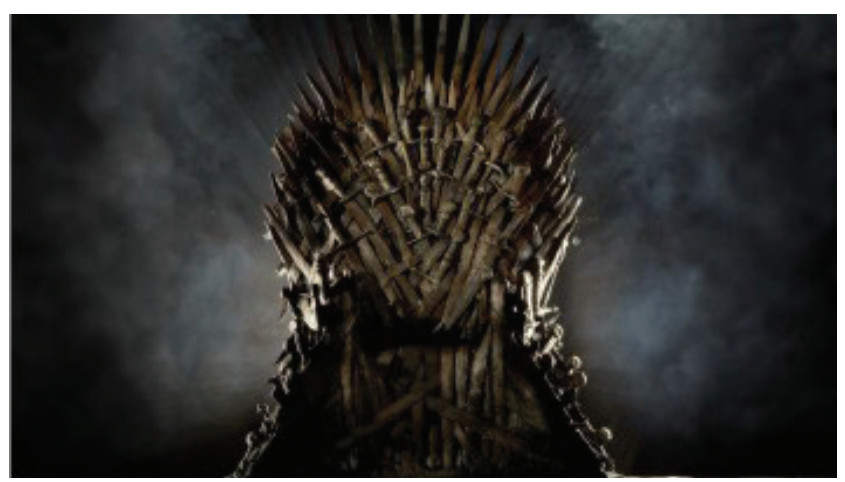

En el contexto de su argumentación, y como caso prínceps, Wajcman (2018) se refiere a la serie recientemente concluida, Game of thrones (David Benioff y D.B. Weiss, 2011) y la define como "la guerra de la mujeres". En efecto, en esta historia plena de todas las versiones que cobra la violencia en la lucha por el poder, las mujeres son tanto víctimas como victimarias. Pero lo fundamental es que en esta ficción de género fantástico e inspiración medieval, una serie de mujeres ocupan los roles protagónicos y son responsables por las acciones que jalonan la trama narrativa. Quizás el mayor hallazgo del guión -y de la saga en la que está basado, $A$ song of ice and fire, de George R. R. Martin (1996)- sea que no se trata de un único personaje femenino, sino, justamente, de una serie.

En efecto, las heroínas de GOT son muchas y hay para todos los gustos, en un guión que parece hecho para desplegar una diversidad de respuestas a la pregunta so- bre qué es una mujer. Las cuatro principales encarnan versiones de profundas raíces culturales y trazan entre ellas dos contrapuntos. Antes de seguir, la fórmula de rigor: Spoiler Alert!

Cersei, la bella y despiadada hermana Lannister, es algo así como el negativo de Medea, capaz de toda crueldad con tal de ver a sus hijos encaramados en el trono. Como bien dice su hermano y amante en uno de los capítulos conclusivos, "las peores cosas las hizo por sus hijos", rubios de padres rubios y nacidos del incesto, los tres muertos trágicamente según la profecía auto-cumplida que signó la vida de la archi-villana de la saga, quien, no casualmente, acabó convertida en reina usurpadora.

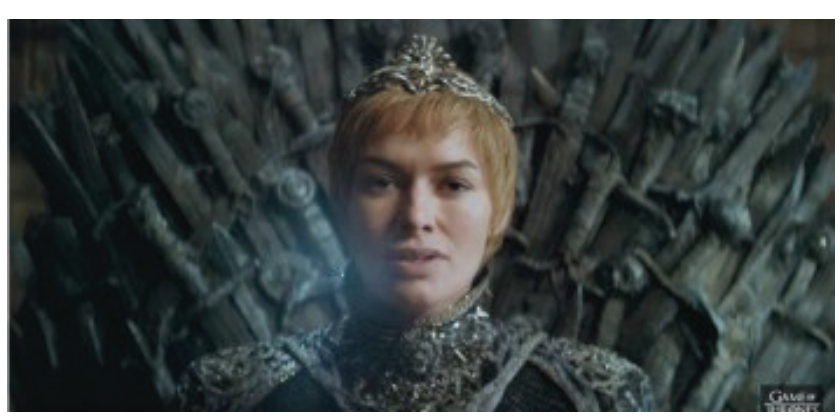

"Daenerys de la Tormenta, La que no arde, Rompedora de cadenas, Madre de Dragones", es la heredera Targeryen, que tras ser vendida por su hermano al jefe de una tribu de rústicos guerreros, enamorarse de su violador, enviudar y dar vida a tres dragones sobre los cuales se pasea con su larga y blonda cabellera, se lanza a recuperar el Trono de Hierro. Durante siete temporadas "Dany" se erige como el reverso de Cersei, una madre buena que ajusticia a los malvados y libera esclavos para engrosar su ejército. El personaje que inflamó las expectativas de los cultores del feminismo más ingenuo, que quisieron ver en ella las supuestas bondades del poder en manos de una mujer, acabó virando al furor destructivo, mostrando de modo intempestivo el reverso de todo Ideal, sellando su destino de Madre de la controversia suscitada por el final de la historia.

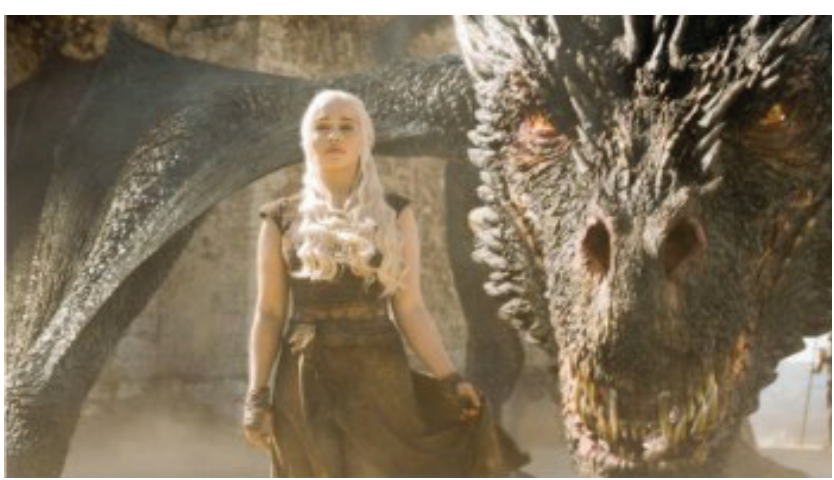


Arya, de la casa Stark, quien desde pequeña reniega de los semblantes femeninos y se entrena con la espada, se convierte en vengadora, tras presenciar la decapitación de su padre y llegar tarde a la Boda sangrienta en la que apuñalan salvajemente a su madre, hermano, cuñada y sobrino por nacer. En adelante, con una lista al mejor estilo Kill Bill (Tarantino, 2003), completa su entrenamiento como asesina "sin rostro", pudiendo adoptar cualquier fisonomía. Convertida en joven mujer, será Arya quien, munida de su pequeña espada, mate al Rey de la Noche, salvando al mundo de las tinieblas. Por fin, la vengadora logra sortear la trampa sacrificial y, tras rechazar el amor de un hombre, se marcha sola a descubrir el mundo desconocido.

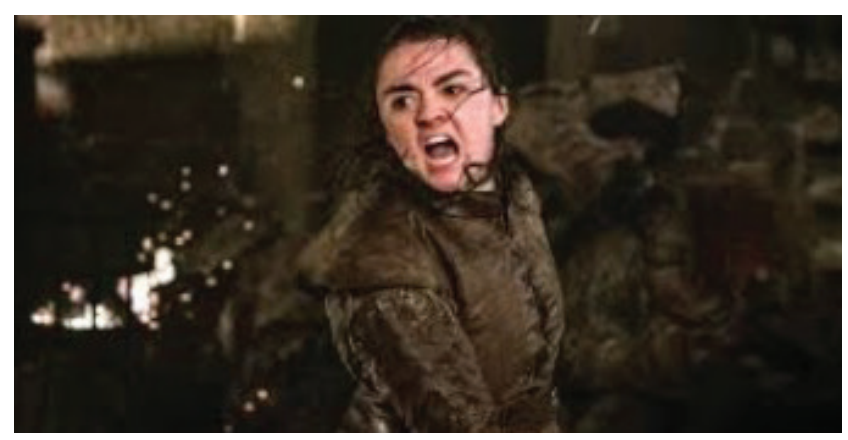

Su hermana Sansa, por el contrario, es una jovencita bella, ingenua y con aspiraciones matrimoniales y monárquicas, que queda cautiva en la corte de los Lannister, donde sufre toda clase de maltrato y es casada con un enano en vez del rey prometido. Por fin, logra regresar a su hogar, pero acaba en manos del sádico violador que lo ha usurpado. Todo eso hizo falta, dice Sansa al final, para dejar de ser "el pajarito" y convertirse en la Reina del Norte, que salvaguarda familia, casa y reino.

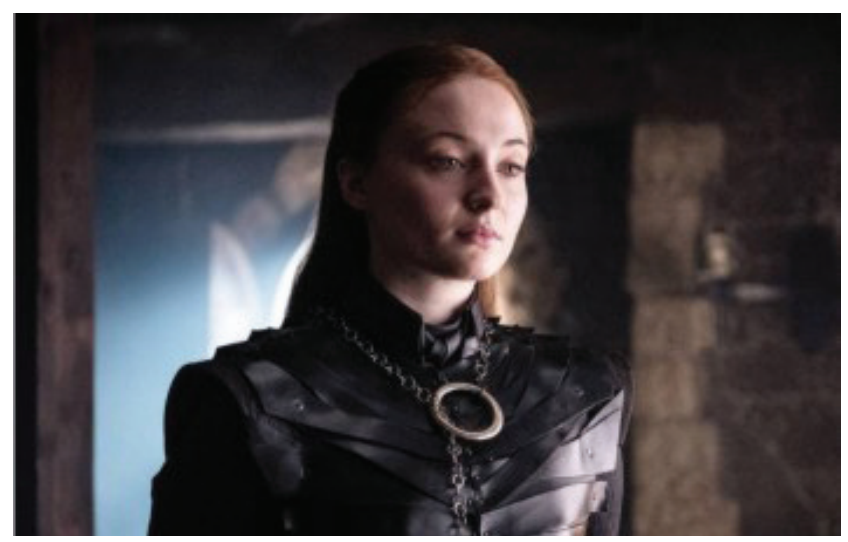

La serie podría ampliarse, puesto que hay muchas, muchas más -la noble y caballeresca Brienne de Tarth; Melissandre, la Diosa Roja que revive muertos y lanza profecías; Shireen Baratheon, la dulce niña con psoriagris, sacrificada a los dioses; Yara, la capitana lesbiana que comanda la flota de los Greyjoy; Margaery, la seductora y ambiciosa princesa Tyrell y su abuela Olenna,; Missandei, la fiel dama de compañía que muere clamando venganza; Ygritte, la "salvaje" que le espeta al protagonista la frase inolvidable, "No sabes nada, Jon Snow"...- pero con esta muestra alcanza para situar lo que importa.

En primer lugar, el show mostró muy crudamente que la guerra se libra sobre los cuerpos, los de las mujeres y los niños principalmente, y que, por ende, la violación, es un acto de dominación y disciplinamiento, tal como plantea Rita Segato (2016).

Pero también, y al mismo tiempo, las heroínas de serie cobran protagonismo y no escatiman recursos, sobrenaturales o no, para alcanzar sus objetivos, en una lucha por el poder, que como tal, cumple con todas las premisas fálicas: salvaguardar el hijo, el padre, la dinastía, el trono, etc. Es que las mujeres, según las fórmulas de Lacan, también se inscriben bajo esta lógica, y son capaces de ir muy lejos en esa dirección, de suerte que las heroínas de GOT resultan un poco alocadas o enloquecidas, incluso francamente chifladas. "Toda la cuestión es que la ilimitación está en el corazón mismo del mundo. Profundamente" dice Wacjman (2018, p. 30), porque en un mundo donde el Otro no existe, los límites se evaporan. Sin embargo, no hay que confundir rápida e ingenuamente lo sin límites con lo femenino, a riesgo equiparar la mujer con la locura, acorde con un arraigado prejuicio machista. Ciertamente, lo femenino según Lacan (1958-1959) implica un más allá del falo, es decir, un goce suplementario, que se caracteriza por ser deslocalizado, indeterminado y sin bordes precisos. Y, en efecto, hay cierta locura que tiene lugar cuando un sujeto, independientemente de su posición sexuada, pierde o deja caer los amarres fálicos y se adentra, cual Antígona, en la zona incandescente de Das ding, con consecuencias nefastas, las más de las veces. Pero ni ese gesto implica siempre una posición ética como la de la heroína de Sófocles, ni toda pérdida de los límites supone ese goce singular. Tampoco lo femenino se presenta necesariamente bajo las versiones trágicas de la desmesura.

\section{Lo femenino, un destello}

Entre las múltiples resonancias de una de las series con mayor audiencia de la historia, sin duda el debate formulado como "feminismo o misoginia", cosechó los 
alegatos más fervorosos tras finalizar la serie, principalmente en torno a Daenerys, la heroína favorita de millones que acabó haciendo arder una ciudad entera, y sin que ello fuera necesario para tomar el poder. En resumidas cuentas, se leyó como feminista el ascenso de Daenerys y como misógino su giro destructivo, convertida en despiadada asesina de masas. Esquivando esta falsa antinomia, el devenir de la súper-heroína de GOT hace posible situar algunas cosas.

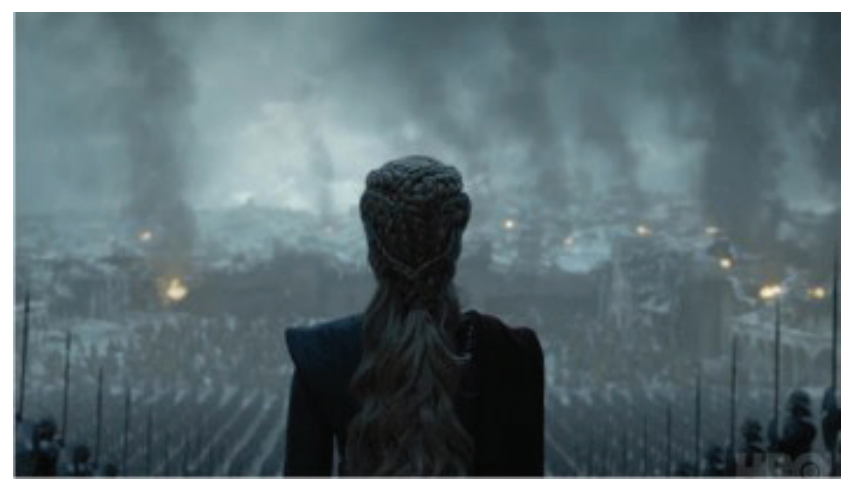

Más allá del desenlace, que lejos de construir la trama de modo cuidadoso como sucedía en las temporadas anteriores, resultó un tanto apresurado y desconcertante, los guionistas se encargaron de situar una serie de hechos que darían cuenta del cambio abrupto de la Madre de Dragones, más allá de la herencia de su dinastía, signada por la locura. Se trata de una serie de pérdidas: en primer lugar, su más fiel súbdito y enamorado, Sir Jorah, muere en la batalla contra los muertos redivivos; a continuación, asesinan a uno de sus hijos-dragones, y a la vez, el dragón, símbolo de su poderío sobrenatural e invencible, se muestra como un animal mortal; en tercer lugar, secuestran y asesinan a su consejera y amiga, la ex esclava Missandei, que muere incitándola a la destrucción; a continuación, su amante se revela como su sobrino, y además, legítimo heredero del trono, por lo cual el significante en el que sostuvo su vida entera, es puesto en cuestión; por último, él no sólo se niega a mantener el secreto, sino que le ofrece su pleitesía, pero le niega el amor. Así, Daenerys pierde, una a una, todas las referencias fálicas que la sostenían en el lugar de la madre buena, Rompedora de Cadenas, que reclamaba legítimamente el trono de la usurpadora y malvada Cersei. Si bien es cierto que ya antes había dado algunas muestras de impiedad, quemando sin vacilar a quienes no se arrodillaran para reconocerla como reina, estos momentos se resignifican retroactivamente en el desenlace. Por fin, sin poder hacer pie en el Otro, se erige a sí misma como un Otro terrible, proclamándose liberadora del mundo y prometiendo reinar por el miedo, habiendo quedado por fuera del amor. De modo que, sin bien el guión apunta al enloquecimiento que tendría lugar cuando el límite de la función fálica deja de operar, la distinción pasa por la respuesta del sujeto, es decir, justo allí donde se sitúa la responsabilidad en términos éticos, y, valga la redundancia, subjetivos. Para decirlo de un modo bruto y así despejar toda duda sobre lo supuestamente femenino de su locura final, Daenerys no es Antígona. Por el contrario, es la Madre de Dragones que responde redoblando la apuesta por el poder, según la lógica del lado masculino de las fórmulas de la sexuación. Si antes representaba el Ideal al modo de la masa freudiana, ahora se ubica como quien encarna la Excepción (Freud, 1921). Toma entonces la pendiente del líder delirante y mesiánico, con una clara alusión a la figura de Hitler cuando se dirige a sus seguidores, detalle que muestra bien la clase de locura de la que se trata: la del desenfreno cuando se rechaza la castración.

Así las cosas, solo resta agregar que si lo femenino, en el sentido lacaniano del término, tiene lugar entre las heroínas de GOT, es sólo aquí o allá, apenas un destello... Es eso que asoma cuando un sujeto sale, al menos por un instante, de la mortificación fálica, con el consecuente saldo vivificante. Cuando Sansa sonríe diciéndole al enano que fue el mejor de sus maridos, o Cersei, frente a la muerte inminente, se entrega por fin sin reparos al amor de su vida; o la pequeña Arya renuncia a la venganza sacrificial para poner límite a la pulsión de muerte encarnada por el Rey de la Noche; o cuando Ygritte le dice al protagonista, "Si tenemos que morir, moriremos. Todos los hombres mueren, Jon Snow. Pero antes vamos a vivir." 


\section{Referencias}

Bender, L. (productor) y Tarantino, Q. (director). (2003). Kill Bill [cinta cinematográfica]. Estados Unidos: Miramax. Benioff, D. y Weiss, D.B. (productores). (2011). Game of Thrones [serie televisiva]. Estados Unidos: HBO.

Freud, S. (1921): "Psicología de las masa y análisis del yo”, en Obras completas, vol. XVIII Buenos Aires: Amorrortu. Lacan, J. (1958-1959): El Seminario. Libro 6. El deseo y su interpretación(1958-1959). Buenos Aires: Paidós. p. 417. Lacan, J. (1982): El Seminario. Libro 20. Aun (1972-1973). Buenos Aires: Paidós.

Lacan, J. (1999): “Ideas directivas para un congreso sobre sexualidad femenina”, en Escritos 2. Buenos Aires: Siglo XXI. Miller, J.-A (2005): El Otro que no existe y sus comités de ética. Buenos Aires: Paidós.

Segato, R. L. (2016): La guerra contra las mujeres. Madrid: Traficantes de sueños. p. 57.

Wajcman, G (2018): Les séries, le monde, la crise, les femmes, Paris: Verdier. 